\title{
UNRELIABLE MARKETS AND PERISHABLE PRODUCTS
}

\author{
Robert W. Fraser \\ Department of Economics \\ University of Western Australia \\ Discussion Paper 84.11 \\ September 1984
}

ISSN 0811-6067

ISBN 0864226640 
UNRELIABLE MARKETS AND PERISHABLE PRODUCTS *

by

R.W. Fraser

Department of Economics

The University of Western Australia

Nedlands, W.A. 6009

* I would like to thank an anonymous referee for helpful comments. 


\section{ABSTRACT :}

This paper considers the behaviour of a farmer facing an unreliable market for his perishable product. In the context of a simple model, where unreliability is characterised as demand uncertainty at the going market price, the optimal responses of a risk averse farmer both to the introduction and to an increase in the level of unreliability are analysed. Conditions determining these responses are described and are shown to contrast markedly with the conditions determining a farmer's responses to uncertainty in other parameters such as price. Finally, the policy implications of the paper are discussed, with particular reference to the problem of unstable supply. 
Many of the commodities sold by agricultural producers are perishable. Whether or not this perishability is important to the producers will, however, largely depend on the reliability of the markets for such commodities. Clearly, if a producer can always dispose of his output at the sale price, the perishability of this output is of no consequence. If, on the other hand, the producer faces some uncertainty about selling all his output at the sale price, this output's perishability becomes a consideration. This is particularly so if the producer has no power to alter the price for sale of his product, such as is often the case in regulated agricultural markets.

The potential importance of unreliable markets in conjunction with the perishability of agricultural products seems not to have been acknowledged in the literature. This may stem from a tendency to overlook this aspect of a producer's uncertain environment and instead concentrate on more straightforward uncertainties such as the uncertainty of price for sale of output and the uncertainty of output from a given planned production. Nevertheless, in view of its potential importance it would appear that some consideration of this problem is worthwhile.

To this end, it is possible to draw to some extent on the literature on stochastic rationing which examines the behaviour of agents facing uncertainty about the amount of a good that may be bought or sold (see, for example, Hymans (1966), Green (1980), Svennson (1981), Fraser (1984)). The only applications of this general problem to the area of agricultural economics seem to be those of Iivingstone and Hazelwood (1979) and Kanbur (1980) in the context of uncertain water availability for irrigation. ${ }^{1}$ Honkapohja and Ito (1980)) and electricity supply policy (e.g. Rees (1976)). 
The behaviour of a risk averse agricultural producer facing an unreliable market for a perishable product remains, however, to be examined.

The aim of this paper is to undertake such an examination. This will be done using a simple model of a risk averse farmer planning to produce a perishable good in the face of an unreliable market. The market is assumed to be unreliable in the sense that the farmer faces uncertainty about the demand for his output at the sale price. If demand turns out to be less than output then the surplus output will perish, while if demand turns out to be more than output then the extra demand will be unsatisfied. In the context of this model the paper will examine the effect on the farmer's planned production of introducing unreliability and of increasing unreliability.

The plan of the paper is as follows: Section I sets out the model which is based on that used by Newbery and stiglitz (1981). It is shown in this section that the effect of the introduction of unreliability into the market depends on whether or not the farmer was initially rationed in his sales. In particular, if no such rationing exists then the introduction of unreliability results straightforwardly in a reduction in planned production. Section II analyses the effect of increased unreliability, represented by increased uncertainty of demand, on the farmer's behaviour. Furthermore, the farmer's response to this change is contrasted with more familiar responses such as to a change in the level of price uncertainty, in order to show the unusual consequences of unreliability for the behaviour of farmers. Section III concludes the paper and discusses its policy implications.

\section{SECTION I THE MODEL}

The basic model of a risk averse farmer used by Newbery and stiglitz (1981, Ch.6) assumes that the only input to production is the farmer's own 
labour, that he produces a single crop, and that his objective is to maximise his utility which itself is separable in income and leisure. These assumptions imply that, in the absence of uncertainty, the farmer will attempt to maximise by choice of labour input:

$U$ (I) - W. $\ell$

where:

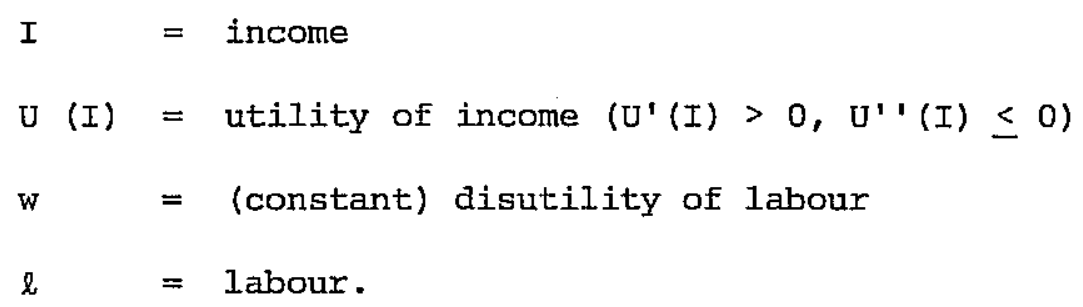

In this model uncertainty for the farmer could be introduced in a number of ways. For example, Newbery and stiglitz consider uncertainty of both price and output, where the uncertainty of output arises in the production process. In what follows the farmer, is assumed initially to face only uncertainty of demand for his output. Uncertainty of price is subsequently introduced, but the absence of uncertainty from production is maintained essentially to simplify the analysis.

Given these assumptions, the unreliability of the farmer's market means his actual sales at the sale price will be the lesser of realised demand (x) and actual (= planned) production (y). This implies:

$$
I=\left\{\begin{array}{l}
\mathrm{px} \text { for } \mathrm{x}<\mathrm{y} \\
\mathrm{py} \text { for } \mathrm{x} \geqslant \mathrm{y}
\end{array}\right.
$$

Expected utility can thus be written as:

$E(U(I))-w \cdot l$

$$
=\int_{0}^{Y} U(p x) f(x) d x+\cdot \int_{Y}^{\infty} U(p y) E(x) d x-w \cdot l
$$

where:

$$
\begin{aligned}
& \mathrm{p} \quad=\text { price } \\
& \mathrm{f}(\mathrm{x}) \quad=\text { subjective probability density governing uncertain demand. }
\end{aligned}
$$


Taking the derivative of (1) with respect to $\&$ gives the farmer's first order condition ${ }^{2}$ :

$$
\int_{Y}^{\infty} U^{\prime}(p y) \cdot p \cdot g^{\prime}(l) f(x) d x-w=0
$$

where:

$$
y=g(l)\left(g^{\prime}(l)>0, g^{\prime}(l) \leq 0,\right.
$$

which can be rearranged to give:

$$
U^{\prime}(p y) \cdot p \cdot g^{\prime}(l) \int_{Y}^{\infty} f(x) d x=w .
$$

Equation (2) says quite simply that, at the optimum, the expected marginal utility benefit of satisfying otherwise foregone demand by extra productive effort should equal the marginal disutility of this effort.

To see the effects of the introduction of unreliability of sales, note. from (2) that with no rationing and no uncertainty about demand: 3

$$
\int_{y}^{\infty} f(x) d x=1 \text {. }
$$

Therefore, with some probability of sales being less than production:

$$
\int_{y}^{\infty} f(x) d x<1,
$$

the balance of (2) can only be maintained by a reduction in effort (and consequently production). Furthermore, it can be seen from (2) that this result holds even if the farmer is risk neutral (U'(I) is constant). In

2. The second order condition is satisfied by the diminishing probability of demand exceeding production, $U^{\prime}(I) \leq 0$ and $g^{\prime \prime}(l) \leq 0$. Notice that the specific effects of changes in $y$ on the limits to integration cancel out.

3. By no rationing is meant that demand is always large enough for the producer to be able to sell his desired output. 
other words, the introduction of unreliability as defined reduces the benefit from marginal effort. Consequently, the farmer's optimal level of effort will be reduced, independently of whether he is risk averse or risk neutral.

If there is rationed demand at some level $x_{r}$ so that the producer is constrained to produce below his desired level:

$$
\mathrm{U}^{\prime}\left(\mathrm{px}_{x}\right) \cdot \mathrm{p} \cdot \mathrm{g}^{\prime}(\ell)>\mathrm{w} \cdot
$$

In this case, the introduction of some uncertainty about the level of rationed demand may justify an increase in production above the original rationed level. Such an outcome depends essentially on whether, with the introduction of uncertainty, the expected marginal utility benefit of production at the original rationed level exceeds the marginal disutility of effort at this level. 4

\section{SECTION II INCREASED UNRELIABILITY}

In this section an attempt is made to evaluate the effect on the farmer's optimal level of effort of an increase in the unreliability of his market. This is characterised by an increase in the level of uncertainty of demand.

The standard approach in the literature to evaluating the effects of increased uncertainty in a particular parameter is to apply the RothschildStiglitz methodology. ${ }^{5}$ Unfortunately, as pointed out by $\operatorname{Kanbur}(1980,1982)$, where the parameter in question affects the agent's decision rule in a "kinked" fashion, such as is the case here for uncertain demand (see equation (1)), the Rothschild-stiglitz methodology is no longer adequate. ${ }^{6}$

4. See Fraser (1984) for further details.

5. This approach determines whether the agent's first order condition is convex or concave in the uncertain parameter, thereby determining whether the value of this condition increases or decreases for a probability density with "more weight in the tails". See Rothschild and Stiglitz (1970) for details.

6. The problem is that the "kink" implies a discontinuity in the derivative of the agent's first order condition so that the convexity (concavity) check cannot be simply applied. 
Kanbur (1980) goes on to consider special cases of this problem, such as the irrigation example mentioned above, and to derive conditions with which the effects of increased uncertainty may be determined. These conditions represent a combination of the usual restrictions on the characteristics of the agent's risk aversion (see, for example, Hey (1981) pp.40-42) and a further condition regarding changes in the agent's subjective probability density function. In the context of the example considered in this paper, the latter condition refers to the probability of demand exceeding (or falling short of) production. Applying this condition to (2) it can be seen that if increased uncertainty of demand (in the Rothschild-stiglitz sense) results in increased (decreased) probability of demand exceeding production, then the farmer's optimal level of effort wili increase (decrease), independently of the characteristics of his risk aversion. ${ }^{7}$ This independence follows from the constancy of marginal utility with respect to foregone demand in (2) and is clearly in contrast to Kanbur's results where some restriction is required on these characteristics.

The Rothschild-stiglitz measure of increased uncertainty is, however, a relatively general measure and some further insight into the problem of increased unreliability of markets for perishable products can be gained by considering the less general "Sandmo" measure of increased uncertainty (see Sandmo (1971)). This measure of increased uncertainty "represents a stretching of the probability density function (without apparent change in its shape) around a constant mean". ${ }^{8}$ More specifically, writing:

7. Note, however, the minimal restriction that $\mathrm{U}^{\prime}(\mathrm{I}) \leq 0$ is required in order to establish the (negative) sign of the second order condition.

8. Hey (1981), p.31. 


$$
x=\gamma(x-\bar{x})+\bar{x}
$$

where:

$\overline{\mathbf{x}}=$ expected demand,

a marginal increase in $\gamma$, evaluated at $\gamma=1$, can be interpreted as increased uncertainty of demand with no change in expected demand. Substituting

(3) into (2) and differentiating with respect to $\gamma$

gives:

$$
-U^{\prime}(p y) \cdot p \cdot g^{\prime}(l) \cdot \frac{\partial F(y)}{\partial \gamma} .
$$

The sign of (4) clearly depends on the sign of $\partial F(y) / \partial \gamma$. Recalling that the Sandmo measure of increased uncertainty involves a stretching of $f(x)$ around $\overline{\mathbf{x}}$, this change implies:

$$
\begin{aligned}
& G(x) \geq F(x) \text { fór } x \leq \bar{x} \\
& G(x) \leq F(x) \text { for } x>\bar{x}
\end{aligned}
$$

where $F(x)$ is the original cumulative density function of $x$ and $G(x)$ is the subsequent cumulative density function of $x$. Therefore:

$$
\frac{\partial F(y)}{\partial \gamma} \gtreqless 0 \text { as } y \leqq \bar{x}
$$

Using (4) and the Implicit Function Theorem, it follows that ${ }^{9}$ :

$$
\frac{\mathrm{dl}}{\mathrm{dy}}>0 \text { as } \mathrm{y}>\overline{\mathrm{x}}
$$

Increased unreliability of sales will increase the farmer's optimal level of effort (and production) if production already exceeds expected demand; while the farmer's effort declines if production initially is less than expected demand. Notice once again that this result is independent of the characteristics of the farmer's risk aversion.

Furthermore, this less general case of increased uncertainty permits a more illuminating intuitive interpretation. In particular, it indicates that if the relative level of utility benefits and costs of productive

9. This Theorem allows the valid total differentiation of (2) with respect to $\ell$ and $\gamma$. 
effort is sufficient to justify a level of output which exceeds expected demand, then an increase in the uncertainty of this demand will result in an even more adventurous level of productive effort. In this situation the farmer finds both that the potential utility loss from foregone income is large enough to warrant a level of production which, on average, will mean a surplus of output, and that an increase in the uncertainty of demand only enhances this potential utility loss, thereby resulting in an increase in productive effort. If, on the other hand, the relative level of utility benefits and costs is insufficient to warrant such adventurous behaviour, then an increase in the uncertainty of demand only serves to enhance the farmer's preference for cautious behaviour in the face of this uncertainty and so his productive effort is reduced. This result is in marked contrast to the usual risk averse response to the increased uncertainty of a parameter. As an example, suppose the farmer faces uncertainty of price in addition to uncertainty of demand and that these two uncertainties are independent. Then (2) may be rewritten as:

$$
E\left(U^{\prime}(p y) \cdot p\right) \cdot g^{\prime}(l) \int_{y}^{\infty} E(x) d x-w=0
$$

and, applying the standard Rothschild-stiglitz methodology, it follows that for an increase in the uncertainty of price, the farmer's optimal level of effort decreases or increases as the second derivative of (6) with respect to $\mathrm{p}$ is negative or positive:

$$
g^{\prime}(l) \int_{y}^{\infty} f(x) d x\left(E\left(U^{\prime} !^{\prime}(P y)(1-R)\right)-E\left(U^{\prime}(p y) \cdot \frac{\partial R}{\partial p}\right)\right)>0
$$

where:

$$
R=\frac{-U^{\prime}(p y)}{U^{\prime}(p y)} \cdot p y
$$


$=$ the farmer's coefficient of relative risk aversion.

Equation (7) shows that if $R<1$ and increasing in $p$, productive effort decreases; while if $R>I$ and decreasing in $p$, productive effort increases. In other words, the farmer's response depends crucially on the characteristics of his risk aversion. ${ }^{10}$

This analysis suggests, therefore, that the combination of an unreliable market and a perishable product represents a quite different problem of uncertainty for a farmer from that of, for example, uncertainty of price. Specifically, in determining the sign of the farmer's production response to increased unreliability in this market, a knowledge of the characteristics of his aversion to risk is not required. Rather, what is required is a knowledge of whether or not the farmer's initial level of production is adventurous or cautious in relation to expected demand.

\section{SECTION III CONCLUSION}

This paper has examined the behaviour of a farmer facing an unreliable market for his perishable product. In so doing it has utilised a simple model of a risk averse farmer producing a single crop with a single input his own labour.

Nevertheless, it is felt that this model is sufficiently rich to demonstrate that in the case of a perishable product, an unreliable market represents a special problem of uncertainty, unlike the usual problems of uncertainty that farmers face. In particular, it has been shown that the factors determining a farmer's response to an increase in the unreliability of a market, represented here by an increase in the uncertainty of demand for the farmer's output, are quite different from those factors determining

10. The sign of an agent's response to a "Sandmo" increase in uncertainty also typically depends on the characteristics of his risk aversion. See, for example, Ishii (1977). 
his response to, for example, an increase in the uncertainty of price. Whereas the latter requires a knowledge of the characteristics of the farmer's risk aversion, the former requires no such knowledge. ${ }^{11}$ what is required, however, in determining the farmer's response to increased uncertainty of demand is a knowledge of whether or not his initial production exceeds or is less than his expected demand. When initial production exceeds expected demand, an increase in the uncertainty of demand will generally increase the likelihood of demand exceeding this production, thus encouraging a positive response of effort. Alternatively, for initial production less than expected demand, an increase in the uncertainty of demand will generally decrease the likelihood of demand exceeding production and effort is consequently reduced. The relationship between production and expected demand was shown in turn to depend on the relative level of utility benefits and costs of productive effort.

From the point of view of policy implications, it is clear from the above analysis that increased unreliability in markets for perishable commodities is particularly destabilising to output. Whereas increased uncertainty of price will simply result in less productive effort as long as farmers are not too risk averse, increased unreliability may result in increased effort if production already exceeds expected demand, and decreased effort if production is less than expected demand, regardless of the extent of the risk aversion to farmers. In other words, increased unreliability tends to encourage the extremes of productive effort in relation to expected demand. It follows from this that a policy of minimising the unreliability of markets for perishable products can only serve to stabilise the relationship between supply and demand in those markets. 
REFERENCES

1. Fraser, R.W. (1984) "Demand Uncertainty and Unemployment", Oxford Economic Papers Vol.36, pp.27-36.

2. Green, J. (1980) "On the Theory of Effective Demand", Economic Journal Vol.90, Pp. 341-353.

3. Hey, J.D. (1981) Economics in Disequilibrium (Martin Robertson, Oxford).

4. Honkapohja, S. and T. Ito (1980) "Inventory Dynamics in a Simple Disequilibrium Macroeconomic Model", Scandinavian Journal of Economics Vol.82, pp.184-1.98.

5. Hymans, S.H. (1966) "The Price-Taker: Uncertainty, Utility and the Supply Function", International Economic Review Vol.7, pp.346-356.

6. Ishii, Y. (1977) "On the Theory of the Competitive Firm under Price Uncertainty: Note", American Economic Review Vol.67, pp.768-769.

7. Kanbur, S.M. (1980) "A General Analysis of Risk Aversion and the 'Risk in Irrigation' Class of Problems: With Applications to the New Soviet Incentive Model and Other Models", Cambridge Economic Theory Discussion Paper, No.30.

8. Kanbur, S.M. (1982) "Increases in Risk with Kinked Payoff Functions" Journal of Economic Theory Vol.27, pp.219-228.

9. Livingstone, I. and A. Hazelwood (1979) "The Analysis of Risk in Irrigation Projects in Developing Countries", Oxford Bulletin of Economics and Statistics Vol.41, pp.21-35.

10. Mills, E.S. (1962) Output and Inventory Policy (O.R.s.A.).

11. Newbery, D.M.G. and J.E. Stiglitz (1981) The Theory of Commodity Price Stabilisation (Clarendon Press, Oxford).

12. Rees, R. (1976) Public Enterprise Economics (Weidenfeld and Nicolson, London).

13. Rothschild, M. and J.E. Stiglitz (1970) "Increasing Risk: 1. A Definition", Journal of Economic Theory Vo1.2, pp.225-243.

14. Sandmo, A. (1971) "On the Theory of the Competitive Firm Under Price Uncertainty", American Economic Review Vol.61, pp.65-73.

15. Svennson, I.E.P. (1981) "Effective Demand in a sequence of Markets", Scandinavian Journal of Economics Vol.83, pp.1-21. 